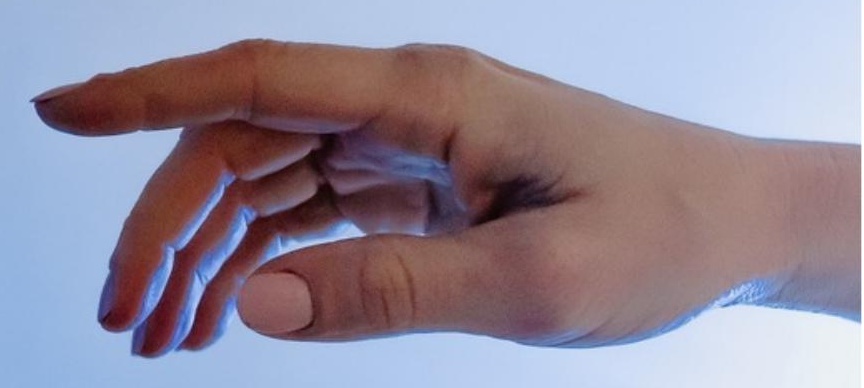

\title{
Philosophy Research Program on Artificial Intelligence and Machine Learning in Oncology
}

\author{
Authors: Ignacio Mastroleo \\ Submitted: $\quad$ 17. January 2022 \\ Published: 24. January 2022 \\ Volume: 9 \\ Issue: 1 \\ Affiliation: National Scientific and Technical Research Council (CONICET), \\ BioThera Research Institute for the Philosophy of Translational \\ Medicine, FLACSO collaborating centre of PAHO/WHO, Buenos \\ Aires, Argentina \\ Languages: English \\ Keywords: Oncology, Artificial Intelligence, Machine Learning, Cancer \\ Categories: $\quad$ Artificial Intelligence, Modeling and Simulation, Medicine \\ DOI: $\quad$ 10.17160/josha.9.1.801
}

\section{Abstract:}

This is a speech addressed to the public of the BioThera Roland Mertelsmann Foundation's meeting on November 5th 2021, Freiburg, with the motto Artificial Intelligence and Translational Oncology: Cancer Treatment 5.0? where I explain and defend the importance of a Philosophy Research Program on artificial intelligence and machine learning in oncology. The speech has been slightly edited for its publication from the oral version. Ignacio Mastroleo National Scientific and Technical Research Council (CONICET) and Programa de Bioetica, Facultad Latinoamericana de Ciencieas Sociales (FLACSO), Buenos Aires, Argentina. ignaciomastro@gmail.com

\section{JOSHA Jounalos semene, Humanities and Arts}




\section{Philosophy Research Program on Artificial Intelligence and Machine Learning in Oncology}

\section{Ignacio Mastroleo}

National Scientific and Technical Research Council (CONICET) and Programa de Bioetica, Facultad Latinoamericana de Ciencieas Sociales (FLACSO), Buenos Aires, Argentina. ignaciomastro@gmail.com

\section{Abstract}

This is a speech addressed to the public of the BioThera Roland Mertelsmann Foundation's meeting on November $5^{\text {th }} 2021$, Freiburg, with the motto Artificial Intelligence and Translational Oncology: Cancer Treatment 5.0? where I explain and defend the importance of a Philosophy Research Program on artificial intelligence and machine learning in oncology. The speech has been slightly edited for its publication from the oral version. 
Dear all, thank you very much for your assistance and thanks to the BioThera Roland Mertelsmann Foundation for the organization of this event. For this talk l'll start first with a short story and then propose three simple questions and try to answer them in turn.

So, the story goes like this...When talking to friends and families, I usually find the common view that technology or biomedical innovations come first and ethics and legal considerations come afterwards. Unfortunately, this is not just a personal view.

It is a misleading and dangerous ethical and legal view.

It is misleading because ethical and legal principles precedes individual action performed by responsible agents (that means, you and me). This is like language and community. They precede individual persons. We are born in a political community and with a certain mother language, (e.g. German or Spanish). So even if we are developing an emergent technology so new that it has not even a name (let's call it algorithm X) and there are no specific written laws or ethical considerations about it yet, our actions will fall into a typified activity (lab research, clinical research, clinical practice, public health practice, etc.) that is already governed by general ethical and legal principles. So someone, at some point, rather sooner than later, will ask us, the responsible agents, to account for those ethical and legal principles of our actions with algorithm X.

The view that scientific innovation comes first, ethics and law later is also dangerous because it blinds us of the perils ahead of us, responsible agents, when developing an innovative biomedical intervention. After this brief general reflection, l'd like to address three simple and concrete questions.

1. The BioThera Foundation's Al Research Center is planning to have a Philosophy Research Program as part of its structure. What would be the main objective of the Philosophy Research Program on Artificial Intelligence and Machine Learning in Oncology (In short, the Philosophy Research Program)?

The main objective of the Philosophy Research Program would be to assist and produce independent research for the Al Research Center (in short, the Center). To achieve this objective the Philosophy Research Program will be designed with a wide scope that will include the two main branches of philosophy, that is, practical philosophy (e.g. clinical \& research ethics, public health ethics) and theoretical philosophy (e.g. epistemology, philosophy of science, logic).

In particular, the Philosophy Research Program will address, in collaboration with the other research groups of the Al Center, the practical and theoretical challenges of how to develop rigorous medical knowledge and interventions 
through $\mathrm{Al} \& \mathrm{ML}$ algorithms and how to translate this knowledge into useful clinical interventions to help patients, the medical community and global society.

2. Why does the Al Research Center need a Philosophy Research Program? Because The Philosophy Research Program can provide a trusted and tested philosophy ecosystem. So, what do you mean by a "trusted and tested philosophy ecosystem"?

By philosophy ecosystem, I mean that it would be more than just practical and theoretical philosophical analysis, or guidelines or frameworks. It would also be a network of active researchers, from relevant institutions, that work in conceptual practical research and assist governmental and research institutions in complex decision making.

For example, The World Health Organization (the WHO) had published in June its Guidance on "Ethics and Governance of Artificial Intelligence for Health " (WHO 2021). The Philosophy Research Program could use this guideline as a general framework for its research work. This will include the collaboration with my parent institution, the Program of Bioethics of the Latina American Faculty of Social Sciences (FLACSO). By a trusted philosophy ecosystem, I refer to my previous collaboration with the BioThera Foundation and IMBS master program since 2014 that includes teaching, mentoring, research publication and successful grants submission. By tested philosophy ecosystem, I refer to the fact that the idea of a "Philosophy Research Program " is not just a new idea. First, the BioThera Foundation has tried and tested this model since 2018 in a smaller scale and funded the Research Institute for the Philosophy of Translational Research in Oncology, within the Program of Bioethics in FLACSO Argentina, of which I'm its director.

Second, most major research groups and institutions doing ground breaking research in biomedical science since the late 1990s have a philosophy research program attached, independently of the name they use. For example, the US Genome Project had the first major Ethics Legal and Social Aspects (ELSA) research program in the history of science, while the Department of Bioethics of the Clinical Centre of the National Institute of Health is another good example of an ELSA research program producing research and serving the $\mathrm{NIH}$ authorities and institutes. Also, pharmaceutical companies have their own bioethics departments (e.g. Research Ethics and Bioethics, Elli Lilly, work on an Ethics Committee of Compassionate Use by Jhonson \& Jhonson in collaboration with NYU Grossman School of Medicine). Consequently, the Philosophy Research Program will be a trusted and tested philosophy ecosystem within that Al Center in this sense explained above.

\section{Would a Research Philosophy Program be a facilitator to the Al Resarch Center?}

The Philosophy Research Program will certainly be a facilitator of the AI Research Center, in the following senses. First, it would have its own autonomous research role together with an assistance and consultancy role aligned to the needs of the 
researchers and the authorities of the Al Research Center. In this sense, it won't be a "mandatory ethics committee" for the researchers of the Al Research Center. Also, in the medium term it can also be a trusted interlocutor with true mandatory clinical ethics and research ethics committees and other normative or regulatory authorities.

Second, it will also be a facilitator in financial terms. It will search and bring independent financing and human resources (e.g. PhD, Postdoc students), not accessible to other research groups by their own, under the umbrella of the Al Research Center (e.g. Alexander Von Humboldt Foundation, DAAD, CONICET-Agencia, Marie Curie, US NIH Fogarty Center, etc.) We hope that this independent funding could be collaborative in its nature, with the other research groups within the Al Center (e.g., shared grant projects, shared PhD, postdoc or master scholarships, etc.). In this sense, I believe that the Philosophy Research Program would be a net facilitator to the Al Research Center.

As a final reflection, as the COVID-19 pandemic has taught us, everything can change abruptly in a short time. In such situations, the crisis forces us to stop acting mechanically, and start thinking how to do things for the first time. Developing Al innovative biomedical interventions to treat cancer ("Cancer Treatment 5.0") is certainly doing things for the first time. Common philosophy principles that precede us, both epistemic and practical, are both a trove of wisdom and a compass we cannot refuse in such uncertain situations. Thank you very much.

\section{References}

World Health Organization (WHO). "Ethics and Governance of Artificial Intelligence for Health." Geneva: World Health Organization. Health Ethics \& Governance Team, June 28, 2021. https://www.who.int/publications-detail-redirect/9789240029200. 